\title{
Primeiro Museu Digital da Odontologia - PMDO
}

\author{
Marcelo Guerino Pereira Couto \\ Mario Pereira Couto Neto ${ }^{2}$
}

1 marcelogpcouto@hotmail.com

2 couto_neto@hotmail.com

\section{INTRODUÇÃO}

Alguns fatores foram importantes na criação do Primeiro Museu Digital da Odontologia - PMDO, como a necessidade a uma adequação ao mundo moderno, que nem sempre é o melhor caminho, mas o homem não pode ficar "a reboque" desta corrida para o mundo virtual e também não pode ficar alheio ao mundo chamado globalizado.

Para que isso acontecesse, foi necessário conhecer a história da Odontologia, saber um pouco sobre museu e também sobre Internet.

Tendo esse conjunto pronto, restou a busca do que veicular no PMDO.

Um pequeno legado sobre a história da Odontologia foi deixado pelo meu pai, o que ajudou muito para darmos início a este projeto.

Vamos conhecer um pouco da história da Odontologia, do museu, da Internet e depois saber como surgiu o PMDO.

\section{A HISTÓRIA DA ODONTOLOGIA}

Joaquim José da Silva Xavier, conhecido como Tiradentes, era afilhado de Sebastião Ferreira Leitão que o ensinou a Odontologia. Nesta época, o tratamento consistia em extrações dentárias com alavancas, boticões rudimentares e as conhecidas Chaves de Garengeot.

O príncipe Regente Don João em 23/05/1800 estabelece, a título provisório, o "Plano de Exames da Real Juntas do Protomedicato" exigindo do candidato à profissão de dentista um exame que constava de conhecimento parcial de anatomia, métodos operatórios e terapêuticos, o comissário desta junta era o cirurgião José Antônio da Costa Ferreira que examinava os cirurgiões médicos e os dentistas.

Por volta de 1840, dentistas dos Estados Unidos chegam ao Brasil e aos poucos substituem os colegas franceses. Em 1850, o Decreto ${ }^{\circ} 598$ criou a Junta de Higyene Pública, que produziu medidas saneadoras, fato que alavancou uma grande evolução para a Medicina.

Com o objetivo de melhorar o ensino, e combater o

charlatanismo, a Faculdade de Medicina do Rio de Janeiro conseguiu que exames fossem aplicados para dentistas e sangradores em 1856.

É importante destacar que os profissionais, principalmente no Rio de Janeiro e em São Paulo, tanto os franceses, os norte-americanos, os portugueses, etc. contribuíram para o desenvolvimento da profissão.

$\mathrm{O}$ número de dentistas vindos dos Estados Unidos crescente, entre eles podemos destacar John Willian Coachman, Willian B. Keys e Carlos Keys que eram pertencentes da mesma família que até hoje representam um grande contingente de cirurgiões-dentistas.

Estes profissionais vindos dos Estados Unidos possuíam grande habilidade em realizar incrustação a ouro, possuíam grande variedade de dentes de porcelana e "pós excelentes para limpar os dentes". Estes profissionais atendiam a nobreza e as famílias de alto poder aquisitivo, enquanto os escravos e o resto da sociedade dependiam de barbeiros e sangradores.

Em 1879, o artigo 24 do Decreto $\mathrm{n}^{\circ} 7247$ determinava: "A cada uma das faculdades de Medicina, ficam anexos: uma Escola de Farmácia, um Curso de Obstetrícia e Ginecologia e um outro de Cirurgia Dentária". Pela decisão do Império n ${ }^{\circ}$ 10 de 04/07/1871, facultava-se às mulheres o direito de realizar matrícula nas faculdades brasileiras que até então eram exclusivas para homens.

Em 25/10/1884, o governo imperial, através do Decreto $n^{\circ} 9311$ de, instituiu oficialmente o Curso de Odontologia nas Faculdades de Medicina na Bahia e do Rio de Janeiro, possibilitando grande desenvolvimento didático e da organização da Odontologia moderna, sendo conhecida como Reforma Sabóia. A data 25 de outubro foi instituída como "DIA DO CIRURGIÃO-DENTISTA BRASILEIRO" em 26/06/1976 por resolução CFO-96, pelo presidente do Conselho Federal de Odontologia Newton Bueno Bruzzi.

Augusto Coelho e Souza, autodidata, ex-discípulo de John Coachman, em 1900 publicou o "MANUAL ODONTOLÓGICO" que fez parte de uma série que serviu de base para a formação de milhares de cirurgiões-dentistas. Formou-se em 1905 e tornou-se notável pelos livros que publicou. Permaneceu como patrono da cadeira $n^{\circ} 1$ da Academia Brasileira de Odontologia e foi referenciado como: PAIDAODONTOLOGIABRASILEIRA. 


\section{CONHECENDO MUSEU}

A palavra "museu" vem do grego mouseion que significa "templo ou morada das musas, ou seja, um local de inspiração divina e de onde provinham aquelas que estimulavam a criatividade dos artistas e intelectuais".

A Biblioteca de Alexandria foi o primeiro prédio a receber esta denominação. A sua destruição em 640 d.C., significou o desuso do termo "museu" no mundo ocidental, embora na Idade Média ocidental tenham existido ao menos dois tipos de instituições que representam a origem do conceito contemporâneo de museu: os "gabinetes de raridades e os tesouros", quase sempre mantidos pelo poder eclesiástico ou pelas casas reais.

No século XVIII o termo museu passa a nomear um espaço de preservação científica, na França o museu aos poucos vai se tornando uma "instituição cultural socialmente reconhecida", embora de caráter elitista passe a representar a possibilidade de universalização democrática do conhecimento e da erudição, com diversas instituições estatais.

No Brasil durante o período joanino, o $1^{\circ}$ museu chega ao Brasil, com a fundação do Museu Real em 1818, hoje Museu Nacional.

Desde então, os museus foram se espalhando pelo Brasil, tendo uma visão mais democrática ao acesso e ao tema do museu.

\section{SOBRE A INTERNET}

A Internet teve seu desenvolvimento iniciado no período da guerra fria oriunda de um projeto de pesquisa militar entre os anos 50 e 60 . Este projeto surgiu através do governo americano como resposta a La Carret de Sputnik que estava sendo desenvolvida pela União Soviética (Lima, 2000). A ideia inicial era permitir que o pentágono se conecta com os mais importantes centros universitários de pesquisa dos EUA para permitir a troca mais rápida de informações e também permitir que o país obtivesse tecnologia de canais de informações caso uma guerra nuclear "começasse".

$\mathrm{O}$ projeto foi se desenvolvendo e se transformou ao longo da história e atualmente, a Internet é um serviço essencial na sociedade.

Universidades, restaurantes e outros comércios já disponibilizam o serviço de forma gratuita para os clientes e a população tem em suas residências e em seus celulares acesso à Internet.

Algumas pessoas fazem críticas ao uso da tecnologia associando a computação e a Internet alegando que ela facilita o operador a conseguir dados que deseja, tornando- se assim mais preguiçoso. Críticas também são presentes no âmbito familiar, algumas pessoas alegam que com a difusão e o aumento do uso da Internet em dispositivos móveis as famílias acabam tendo o seu convívio reduzido.

Porém, a Internet é uma ferramenta muito importante para tornar o conhecimento mais democrático, aumentando o acesso de pessoas às informações e para aproximar pessoas de pessoas e até mesmo pessoa a lugares.

Com apenas 1 "clique", pode-se visitar museus e outros lugares espalhados pelo mundo inteiro. A facilidade que o mundo moderno nos fornece nos permite visitar e conhecer lugares de forma mais rápida sem perder o tempo do deslocamento, espera em filas, problemas com compatibilidade de horário de funcionamento do local com o horário vago do visitante.

Com esta grande comodidade que a tecnologia nos proporciona, museus Odontológicos também foram criados de forma digital.

Essa mescla da antiguidade com a modernidade proporciona um perfeito casamento onde podemos observar a tecnologia de ponta proporcionando uma melhor visibilidade da história, fazendo com que em certos momentos imaginamos ter sido transportados ao tempo passado.

$\mathrm{O}$ avanço da tecnologia nos permitiu dar grandes passos na modernidade como podemos observar no Museu do Amanhã situado na Zona Portuária do Rio de Janeiro onde podemos ter uma previsão de como o nosso planeta estará daqui a 50 anos.

Chegamos ao máximo de podermos visitar um museu e conhecer neste o futuro, como é incrível este contraste visto no Museu do Amanhã citado acima.

\section{O PRIMEIRO MUSEU DIGITAL DA ODONTOLOGIA - PMDO}

O Primeiro Museu Digital da Odontologia - PMDO surgiu da vontade de registrarmos a história da Odontologia de forma digital. Na tarde de domingo do dia 12 de abril de 2015, eu Marcelo Couto e o meu filho Mario Couto Neto, hoje cirurgião-dentista, conversávamos sobre o pequeno acervo de Odontologia deixado pelo meu saudoso pai, Mario Pereira Couto, cirurgião-dentista e professor universitário, momento em que tivemos ideia de montar o Museu Digital. Focamos primeiramente na rede social Facebook e posteriormente no Instagram.

No mundo moderno em que vivemos, muitas vezes, visitar um museu se torna mais difícil por conta do deslocamento, horário de funcionamento e tempo. Mas, desta forma, o acesso acontece através do próprio celular. Porém, deixamos claro que, apesar desta facilidade, a visita presencial não deve ser descartada pois nesta estamos 
motivando, prestigiando o museu e cada vez mais próximos da realidade daqueles momentos passados.

Hoje, no ano de 2020, escrevemos este artigo em momento de pandemia por motivo do coronavírus, conhecido como COVID-19, jamais poderíamos imaginar que em algum momento de nossas vidas estaríamos impossibilitados de ir e vir, de ir a um simples mercado fazer compras de gêneros alimentícios para a nossa família, imaginem ir a um museu.

Com toda a comodidade de acesso aos simples toques, não deixe de visitar os museus, faça este programa com sua família. Nossos filhos, netos, bisnetos e os demais, não podem deixar de conhecer a história viva dos museus, conhecer o passado é importante para viver um bom presente e aguardar o futuro que a Deus pertence.

Redes sociais:

https://www.facebook.com/museudigodonto

@)museuodonto 